\title{
Screening of Geomechanical Risks for Malaysian Development Field
}

\author{
Syed Muhammad Syafiq Syed Najmuddin and Muhammad Aslam Md Yusof ${ }^{a}$ \\ Peroleum Engineering Department, Universiti Teknologi PETRONAS, 32610 Seri Iskandar, Perak, Malaysia
}

\begin{abstract}
Deeper drilling and exploitation of difficult reservoir is the new trend in oil and gas industry. Geomechanics study has, therefore, become a new requirement particularly for oil and gas field development. However, a complete geomechanics study is limited with the number of experts, time consuming and not a straightforward task. Therefore, there is an urgent need of a quick geomechanics screening criterion to be used as a standard guideline to evaluate the high level geomechanical risks and suitable analysis can be recommended for the identified development fields. The aim of this paper is to propose a screening criterion for geomechanical risks study based on four key parameters, drilling, depletion, injection and storage and sand production. The screening approach is designed based on Risk Assessment Matrix (RAM) risk screening where the likelihood is based on a set of scores developed to specific questions. The consequence for each failure scenarios is assessed based on educated estimation of the impact towards people, asset, environment and reputation. Recommendations for geomechanical study are made based on the severity of each failure category on the RAM risk matrix. Fourteen development fields in offshore Peninsular Malaysia, offshore Sarawak and offshore Sabah are selected for the assessment. Based on results, fields in offshore Sarawak and Sabah have higher potential for geomechacnical issues mainly because of their geological settings and formation characteristics. A set of geomechanical study is proposed for each individual field for prudent management of potential geomechanics risk associated with the depletion and EOR injection scheme planned for the fields.
\end{abstract}

\section{Introduction}

Geomechanics is related to the study of rock and soil behavior. There are two major types of geomechanics which are rock mechanics and soil mechanics [1]. Geomechanics deals with soil behavior starting from a small scale to a landslide scale. Presently, it deals with geosciences issues related to mass rock mechanics and mass rock characterization like things applies to high depths or petroleum industry, rock breakage, drilling of rock and tunnel design. As challenging conditions are more frequently encountered because of deeper drilling, exploitation of more difficult reservoirs, more focus on heavy oil, and other factors associated with the gradual depletion of easily recovered conventional oil, geomechanics has become more important to the oil and gas industries [2]. In the past years, geomechanics studies have only being done if it is requested by the field. Though, this practice is not reliable enough in the current world. Thus, a screening criteria spreadsheets need to be developed. It is essential to be used as a standard guideline to evaluate the high level geomechanical risks and suitable analysis can be recommended for every development fields.

To achieve geomechanics study goals, it is very crucial to reduce the risks and costs related to refining drilling programs, making a better predictions of

\footnotetext{
a Corresponding author: aslam.myusof@petronas.com.my
}

production rate and optimizing the development plans of field. The key project objectives are to utilize a set of geomechanics screening criteria and process, assess in drilling, depletion, injection and storage also the sand production. Moreover, this is to assess the geomechanical risk for each individual development field in consideration of RAM risk matrix and rank the field that is affected geomechanically based on the development plans and their geological settings.

\section{Screening Criteria}

\subsection{Drilling}

A big changes in the fracture gradients and pressure of pore in drilling may result in stuck pipe, washouts, unplanned sidetracks and loss of circulation [3]. Therefore, the study of geomechanics helps to enabling either avoidance, identifying geohazards and predicting an operational windows that is safer. The operation of drilling has given an impact on wellbore instability, pack off, stuck pipe, mud loss and drilling induced fault reactivation. Borehole instability or also known as wellbore stability is a condition that is critical for an open hole interval. The causes are the failure mechanically causes by in-situ stresses, erosion causes by circulation of 
fluid, chemical causes by borehole fluid interaction with the formation. When a pipe cannot be removed unless causing any pipe damages and without exceeding the maximum load off the hook of the drilling rigs. This phenomenon can be classified into differential pressure pipe sticking and mechanical pipe sticking.

Moreover, whenever the drilling fluid does not returning to the annulus but flows into the geological formation, it is called the mud loss. During the drilling operation in any well, the existence of lost circulation is considered as a serious problem. The presence of mud loss may cause the loss of high amount of drilling fluid costs and result in loss of humans life [4]. Therefore, a high concern should be put closely on the pits, tanks and flow from the well to ensure a fast assess lost control circulation is being taught well and practiced every time. In addition, the movement along formerly inactive faults is called fault reactivation. This will contribute to alleviate strain within the upper mantle and crust. There are 3 factors that has contributing much which are pore pressure being elevated locally because of hydrocarbon reservoir containing natural gas on the footwall side of the fault, an orientation of fault that is oriented optimally for frictional slip in today's stress field and a compressional stress that increase recently in the postglacial rebound area.

\subsection{Depletion}

Knowledge of deformation of stress within and surrounding the reservoir depletion is important in a multi-disciplinary approach to reservoir characterization, reservoir management, and enhanced oil recovery projects. The most common problems are related with surface subsidence and casing collapse that create substantial difficulties in some reservoirs due to compaction in weak formation [5]. The significant stress changes that occur in high reservoir being depleted can result in drilling new well into deeper target reservoir problematic due to the need to lower mud weights in depleted formations to avoid mud lost circulation. Induce faulting also is part of the possibility for depletion either within or outside the reservoirs depending on the well geological setting.

Excessive subsidence is the sinking of soil due to a major problem in the developing world without any enforcement and regulation and the extraction from groundwater. The pressurized fluid within pore spaces and the rock matrix are the one who support the overburden sediments weight above formation produced. More load is being transferred to the rock matrix especially when the oil and gas production reduces the fluid pressure [6]. Caprock shear failure will happen when pore pressure increases. This is mainly due to the change of phase in the water that results in the reduction of effective-stress.

Reactivation of fault has a lot of effects and consequences. It shears the wellbore which occur when the fault zone of slipped portions is drilled through, the stored elastic energy is being released, the permeability of formation and production-depletion strategies being changed and seismicity is induced [7]. Usually, four thresholds are defined for instability in wellbore, and drilling program design is partly based on trying to keep the mud weight within the safe mud window. Kick, break down, losses and breakout are the common thresholds.

\subsection{Injection and Storage}

Fluid injection induces an increase in the pore pressure and gradient of the pressure at the borehole. The pressure variations affect the materials mechanical equilibrium around the boreholes and changes the in-situ stresses. In theory, the poro-elastic effect does improve the total stresses [8]. Additionally, fluid injection in reservoirs also modifies the thermal and hydraulic equilibrium around wellbore and cause strains to the reservoir as well to the entire sedimentary column. In assessing geomechanical influences during injection and storage for reservoirs, it is essential to evaluate based on the containment characteristic of the formations in terms of risks of leakage through fault, well and top seal. Similarly, the evaluation of the induced subsurface and surface deformation in terms of risk of induced seismicity and ground movement are equally important.

Caprock shear failure is mainly because of steam injection in high pressure within the reservoir is an advantage [9]. However, if these fractures extend and grow to the overlying layers of shale, this may result in failure of shear at the interface of shale which compromise on the ability of containment. Besides that, the propagation fracture of the fluid-driven relates with the process in multiple physical such as the flow in porous aquifer and fracture and also mechanical fractures [10]. In addition, the rate-limiting process for propagation fractures will happen due to the low permeability of aquifer which result in a slow fluid outflow.

An analysis of slip tendency is used to assess the potential of shear reactivation and fractures dilatational in a deep geothermal reservoir which is based on the notion that slip on faults is controlled by the ratio of shear to normal stress acting on the plane of weakness in the in situ stress field [11]. The initiation of fracture coupled with micro seismic events is important to produce extra fractured flow paths that improve the productivity and permeability. However, an undesirable seismicity is caused by a fluid injection that are not being change to the strength of rock conditions and to the in-situ stress field [12].

With the slip tendency analysis the potential for slip along any fault orientation with respect to the ambient stress field is investigated and therefore it is possible to assess the fault reactivation potential. This technique has been used for seismic-risk and fault-rupture-risk assessment in earthquake-prone areas and to understand the relative importance of shearing versus dilation behaviors along faults and bedding planes during deformation.

\subsection{Sand Production}


The reservoir fluid flows causes the formation sand migration [13]. Commonly, the sand production is not desirable and if severe, sand production may require some remedial action to control or prevent production. Basically, unconsolidated sandstone reservoirs are the most prone to sand production where most probably initiated during initial flow or later when reservoir pressure decline or water breakthrough. Continuous sand production is sometimes can be neglected or considered tolerable. However, this way might cause the well to be extremely damaged, the equipment at the surface cannot function very well and the production operation can be killed.

For perforated well, it is also believed that sand production may be initiated from perforation tip, which may be assumed to have a hemispherical geometry after the perforation shape stabilizes through some time of oil or gas production [14]. They studied stress state near a sand arch by considering steady state and incompressible fluid flow. This is done in terms of wellbore pressure, drawdown, frictional angle and formation rock cohesion [15].

It is undeniable that when there is a presence of sand, it will result in a high cost which occur whenever drag forces on sand particles, induced by the flow of fluid and/or solution-gas drive, exceed the forces of intergranular which result in the mechanical integrity loss. Quite a number of authors have realized and point out the problem from both control and prediction points of view. Sand production is considered one of the challenging issues in various steps of field development including borehole instability during production, drilling and IOR/EOR stages is a natural impact of flow of fluid into a borehole from the reservoir [16]. The ordinary production engineer still need to consider relying on the rudimentary predictive techniques being widely used in the world even though there are an existence of sophisticated proprietary computer programs, such as Schlumberger's Impact and Conoco's three dimensional FE models [17].

\section{Methodology}

The framework of the screening criteria and approach comprises of the following:

1. Evaluation aspect category: drilling, depletion, injection and storage, sand production

2. Questionnaire: question, weightage, scoring

3. Risk evaluation: category, impact quantification

4. Risk assessment matrix (RAM)

5. Recommendations

The screening evaluation is categorized into 4 aspects which are drilling, depletion, injection and storage, and sand production. The first 3 aspects directly change the stress state of the formation and thus, closely related to hydrocarbon containment. Meanwhile, the last aspect, sand production is the effect of stress changes in the formation and is not the primary focus of the project.
The screening criteria approach for this project focused mainly on reservoir geomechanics. It is essential to identify the potential issues or problems that might occur for each life cycle of the reservoir so that proper mitigation can take place. There are several main components in the screening spreadsheet that are crucial and needed for evaluation of the geomechanical risks in development fields. These components include major activities, initiating event, threat, hazard and barrier category, weight factor and question response. All of these components are decided after a thorough and several session of discussion between the project team based on team's field experiences and research studies.

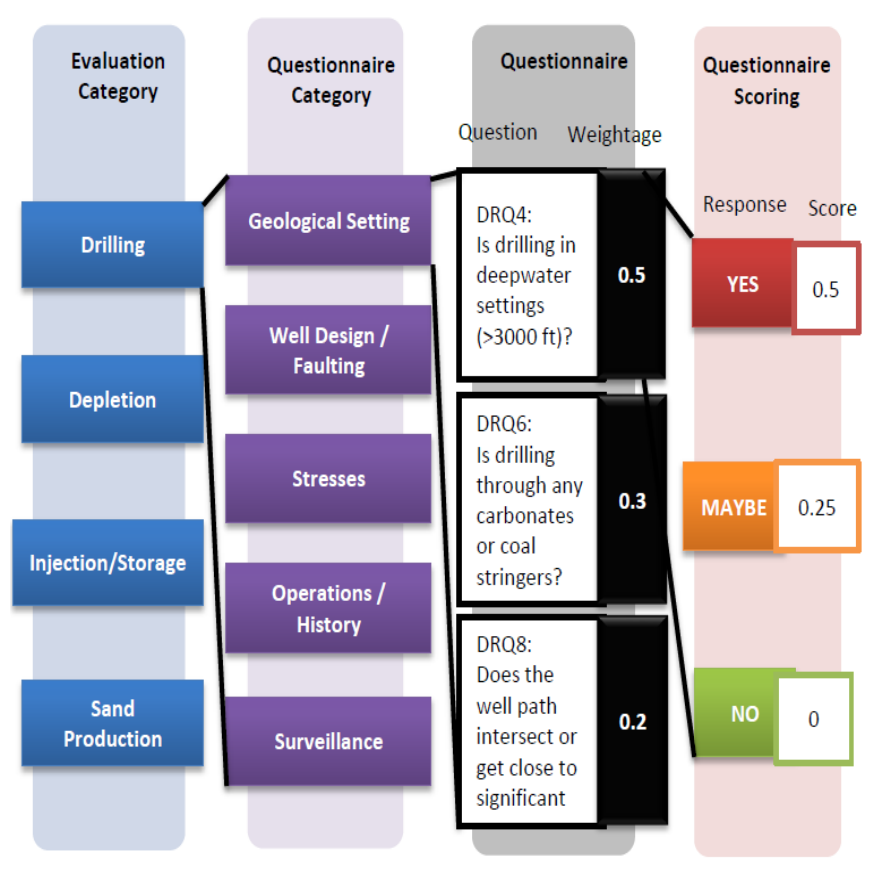

Figure 1: Questionnaire Classifications

There are four major activities being consider in the spreadsheet that includes drilling, depletion, injection and storage as well as sand production (Figure 1). Under each activities, there are number of questions, which also known as the initiating event that have been considered to have effects on geomechanics issues. In order to complete the list of initiating event, there are some deliberations done. For instance, there is a need to ensure that the questions are understandable. Apart from that, it need to make certain that the questions are answerable whereby the information needed is within the asset team scope of work. Last but not least, the number of the questions must be appropriate and not too time consuming for them to answer. Since the questions are closed-ended question, it is decided to use intensity scales i.e. yes, maybe or no as the answering mode for the screening criteria.

In addition, this method is believed to ease the answering process by the asset team. However, if the answer provided is vague the asset team need to explain further in the spreadsheet so that it is able to understand the issues for the specific field that will further help the evaluation process of the geomechanical risk. 
Threat is one of the main components in the spreadsheet. In this project, threat has the definition of issues that are under consideration that might cause by the main activities. For instance in the drilling section, some of the threats are wellbore instability, pack off and stuck pipe, mud loss and drilling induced fault reactivation. This is because while drilling, some of these issues might occur due to changes in the rock formation and in-situ stresses. The purpose of the threat section is to calculate and determine the possibility for the issues to occur for each field.

Hazard and barrier category is included in the screening criteria as well. There are six categories that vary for each of the major activities. The purpose of this section is to ensure that the initiating event developed covers the entire category. It is also to ensure the questions are balanced and all the aspects are being covered. On top of that, weight factor column has been created to accommodate the tracking of the hazard itself. It means that the hazard category and the weight factor are inter-related.

\begin{tabular}{|c|c|}
\hline Injection / Storage Threats Under Consideration: & Normalized Score \\
\hline IST-1 Caprock Shear Failure & 1.00 \\
\hline IST-2 Fracture Propagation into Caprock & 1.00 \\
\hline IST-3 Fault Reactivation - stress-induced & 1.00 \\
\hline $\begin{array}{l}\text { IST-4 Fault Reactivation - Induced Fracture } \\
\text { Interception }\end{array}$ & 1.00 \\
\hline Injection / Storage: Final Score & \\
\hline
\end{tabular}

Figure 2: Normalize score in specific issue

Under each threat, there is also one main component which is the influence factor. The influence factor is to indicate the presence of relation between the initiating event and the threat itself. By having this component, it will be much easier to evaluate the risk for the geomechanical issues for each field. As the score for the influence factor will eventually sum up and a normalized score is being calculated for each threat.

From the normalized score, the risk will be rank using the risk ranking table (Figure 2). The risk ranking is based on the likelihood and the consequences of the event to four main traits which are people, asset, environment and reputation (Figure 3). The final risk index will be automatically calculated whereby the recommended action can be generated based on the risk index itself. This will help to give some idea to the project team on the way forward for all of the fields as well as to categorize the need for geomechanical studies for all the fields.

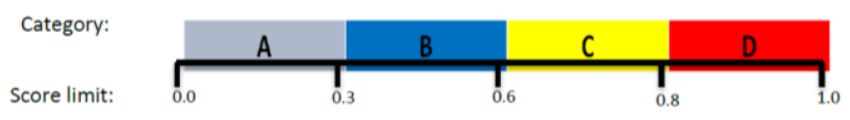

Figure 3: Risk ranking score limit

Risk Assessment Matrix (RAM) is a matrix that is used during the assessment of risk study to define various levels of risk as the product of harm probability categories and harm severity categories (Figure 4). This is a simple mechanism to increase visibility of risks and assist management in decision making. Risk matrices in certain cases experience several problematic mathematical features making it harder to assess the risks. Furthermore, there is existence of error using this matrix. This is because the risk matrices can mistakenly assign higher qualitative ratings to quantitatively smaller risks. For risks with negatively correlated frequencies and severities, they can be "worse than useless," leading to worse-than-random decisions.

In addition, there is also a suboptimal resource allocation problem arises where effective allocation of resources to risk-reducing countermeasures cannot be based on the categories provided by risk matrices. Besides that, it is an ambiguous inputs and outputs problem. Categorizations of severity cannot be made objectively for uncertain consequences. Inputs to risk matrices (e.g., frequency and severity categorizations) and resulting outputs (i.e., risk ratings) require subjective interpretation, and different users may obtain opposite

\begin{tabular}{|c|c|c|c|c|c|c|c|c|c|}
\hline \multirow{3}{*}{ 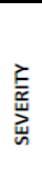 } & \multicolumn{4}{|c|}{ CONSEQUENCES } & \multicolumn{5}{|c|}{ INCREASING LIKEUHHOOD (SCORE LIMIT) } \\
\hline & & & 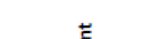 & & A & B & c & D & E \\
\hline & $\begin{array}{l}\overline{0} \\
\vdots \\
\vdots\end{array}$ & 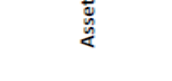 & 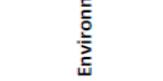 & 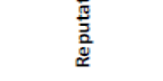 & $>0$ & $>0.2$ & $>0.4$ & $>0.6$ & $>0.8$ \\
\hline 0 & No injury or health effect & No damage & No effect & No impact & & & & & \\
\hline 1 & Slight injury or health effect & Slight damage & Slight effect & Slight impact & & & & & \\
\hline 2 & Minor injury or health effect & Minor damage & Minor effect & Minor impact & & & & & \\
\hline 3 & Major injury or health effect & Moderate damage & Moderate effect & Moderate impact & & & & & \\
\hline 4 & PTD or up to 3 fatalities & Major damage & Major effect & Major impact & & & & & \\
\hline 5 & More than 3 fatalities & Massive damage & Massive effect & Massive impact & & & & & \\
\hline
\end{tabular}

Figure 4: Risk Assessment Matrix (RAM) 
ratings of the same quantitative risks. These limitations suggest that risk matrices should be used with caution, and only with careful explanations of embedded judgments.

The probability of harm occurring might be categorized as 'Certain', 'Likely', 'Possible', 'Unlikely' and 'Rare'. However it must be considered that very low probabilities may not be very reliable. The asset team will only need to answer the spreadsheet by input yes, maybe or no and could add some justification so that the project team able to understand the issue in a correct manner. The evaluation part will be done by the project team based on past experiences, fields' history data and the research studies done.

\section{Results \& Discussion}

Figure 5 shows the drilling score for all fields that have been studied. The final score is the generic results from four drilling threats that were given in the questionnaire for every field team. The four threats are general wellbore instability (DRT-1), packoff and stuck pipe (DRT-2), mud loss (DRT-3) and drilling induced fault reactivation (DRT-4). The score for each threat are gained from the influence factor that vary based on their impact towards each field. The bigger the impact, the higher the weightage it carry where the normalize score value towards ' 1 ' means that the field has a higher risk for the respective threat compared to the normalize score value towards ' 0 '. Final score is obtained by calculating the average score from all threat present. This is to rank the field risk accordingly.

In Figure 5, Field L has the highest final score which is ' 0.6 '. This is mainly due to the high effect of drilling induced fault reactivation. Thus, it is critical to conduct details geomechanics study in order to ensure smooth drilling and production operation in the future. The risk index for this field is ' 2 '. The value is given based on the probability of harm occurring that has been discussed in the methodology section. Therefore, the recommended actions for this risk index is to review offset wellbore stability work. Update the formations stresses (based on any depletions, etc.) and formation mechanical properties (with any new data), and perform appropriate mud weight prediction for the new well trajectorie.

For depletion issue, as shown in Figure 6, Field B has the highest final score which is ' 0.76 '. All fields were ranked based on their final mark in depletion issue. There are four threats that have been considered in depletion issue which are excessive surface subsidence (DPI-1), caprock shear failure (DPI-2), fault reactivation (DPI-3) and compaction/well failure (DPI-4). Based on RAM risk assessment, the risk index for Field B is ' 3 '. Therefore, the recommended actions for this risk index is to perform comprehensive 3-D geomechanical modelling to evaluate the compaction/subsidence magnitudes, top seal integrity and potential of fault reactivation for various depletion scenarios and stages. It is also recommended to request GPS monitoring for subsidence prediction and model updates throughout the field life.

The next geomechanic issue is injection and storage. We evaluated the field based on their risk possibility in four types of threats namely caprock shear failure (IST-1), fracture propagation into caprock (IST2), fault reactivation - stress-induced (IST-3) and fault reactivation - induced fracture interception (IST-4). Based on results shown in Figure 7, Field D has the highest final score which is ' 0.74 '. This is mainly due to the high effect of caprock shear failure and fault reactivation - stress-induced. Meaning that, Field D will be the most prioritize field to be done research on geomechanics compared to other fields. The risk index for this field is ' 3 '.

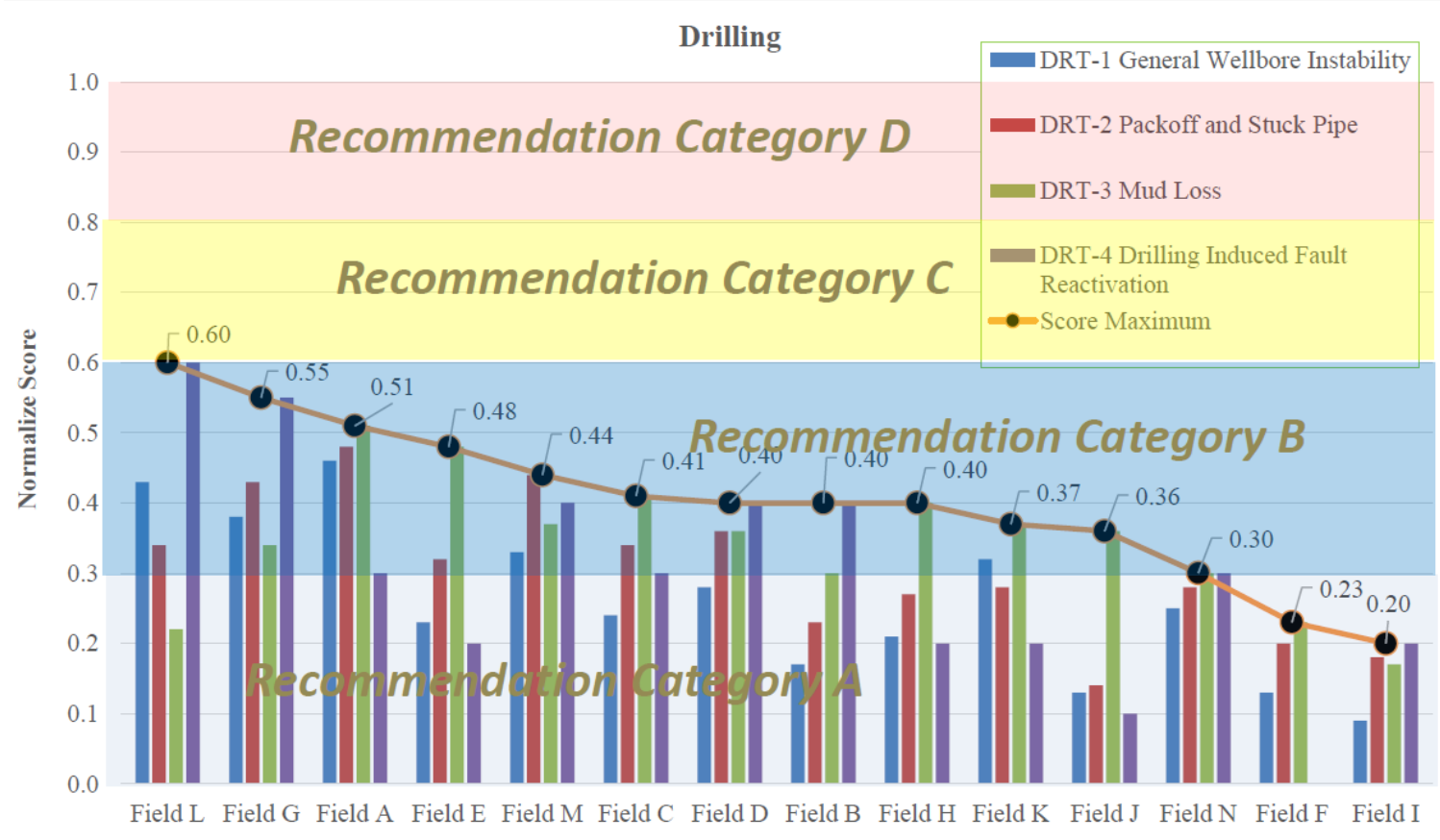

Figure 5: Drilling score for all fields 


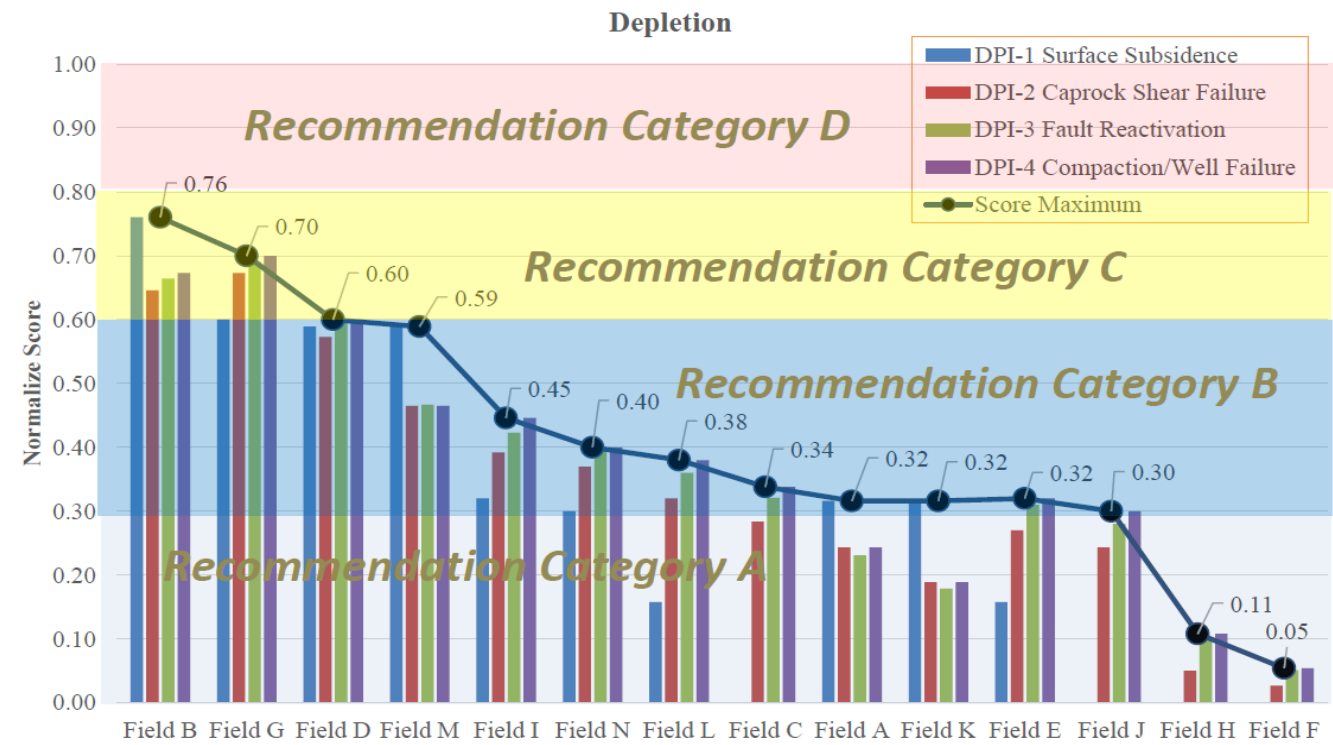

Figure 6: Depletion score for all fields

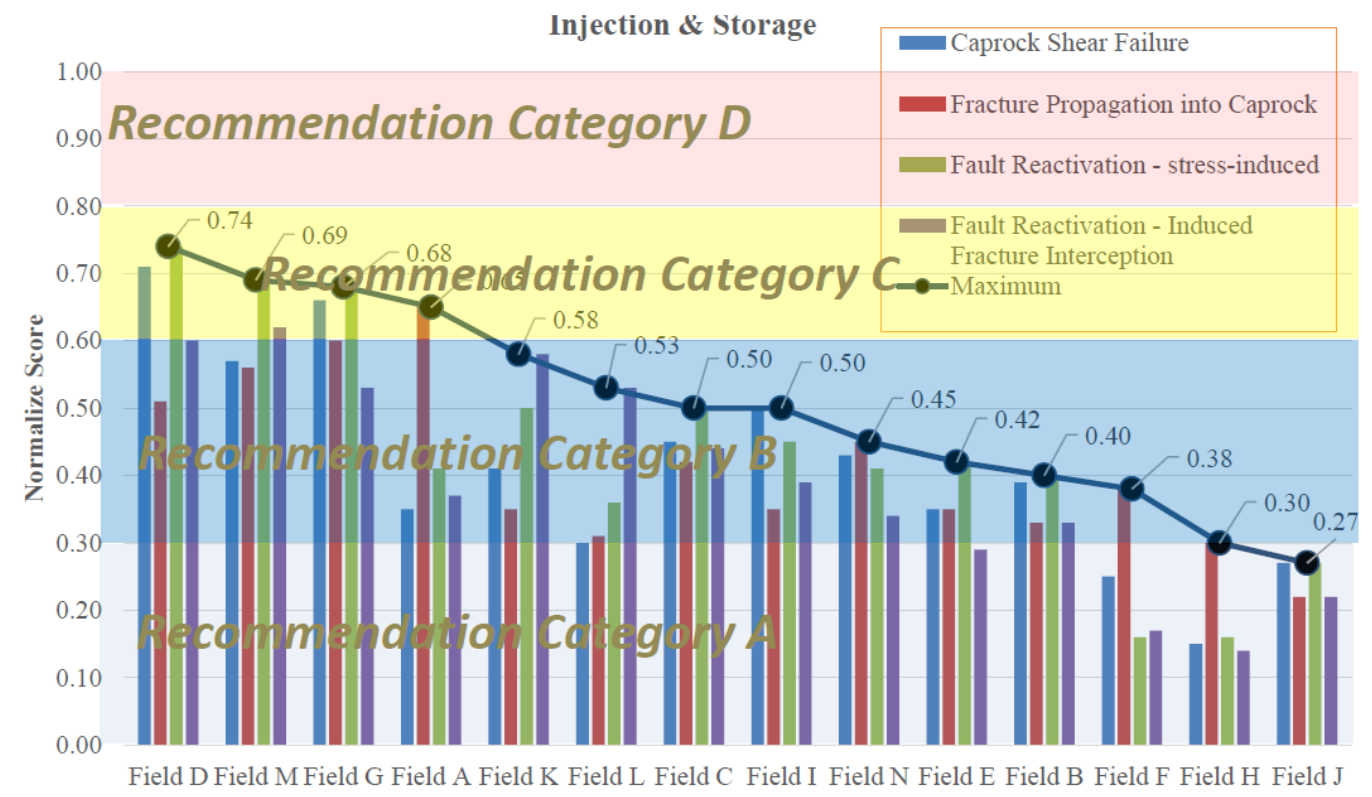

Figure 7: Injection and Storage score for all fields

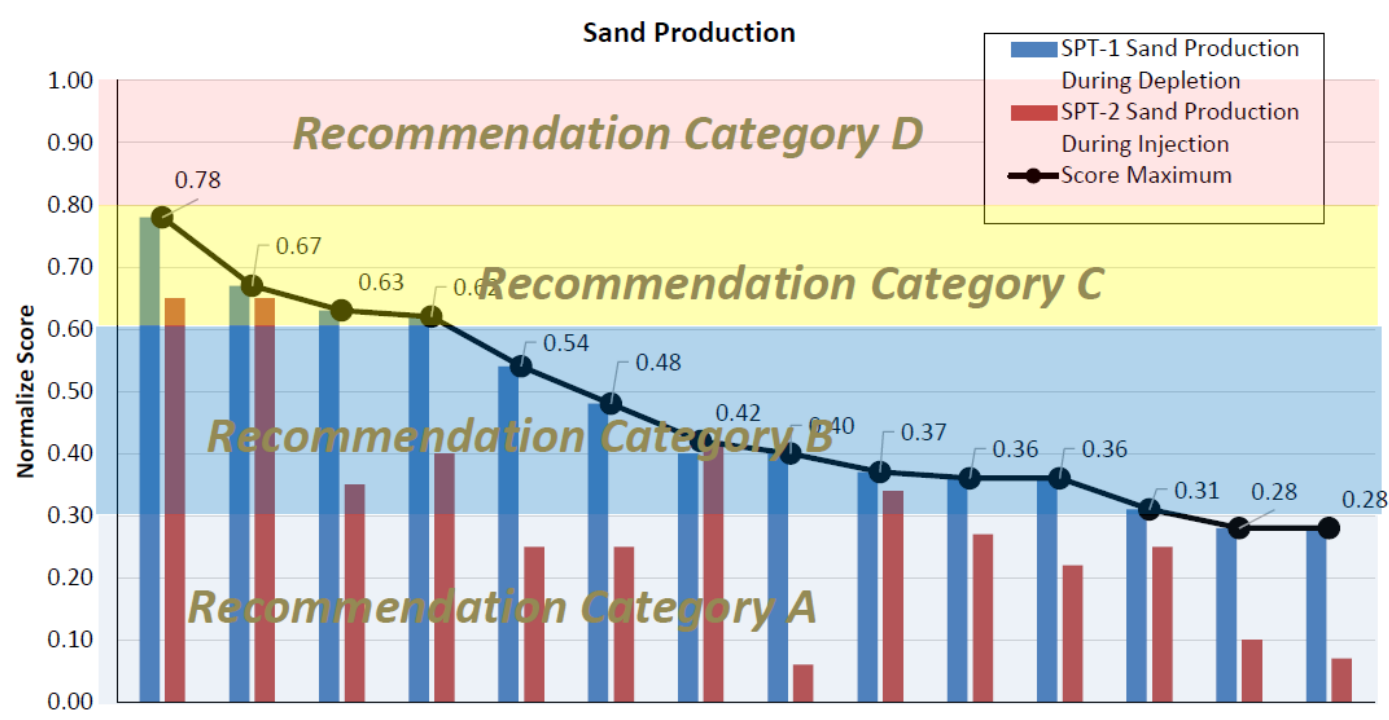

Field $\mathrm{G}$ Field $\mathrm{M}$ Field $\mathrm{B}$ Field $\mathrm{A}$ Field $\mathrm{E}$ Field $\mathrm{I}$ Field $\mathrm{D}$ Field $\mathrm{J}$ Field $\mathrm{L}$ Field $\mathrm{K}$ Field $\mathrm{N}$ Field $\mathrm{C}$ Field $\mathrm{H}$ Field $\mathrm{F}$

Figure 8: Sand Production score for all fields 


\section{Overall Ranking ( Maximum Score)}

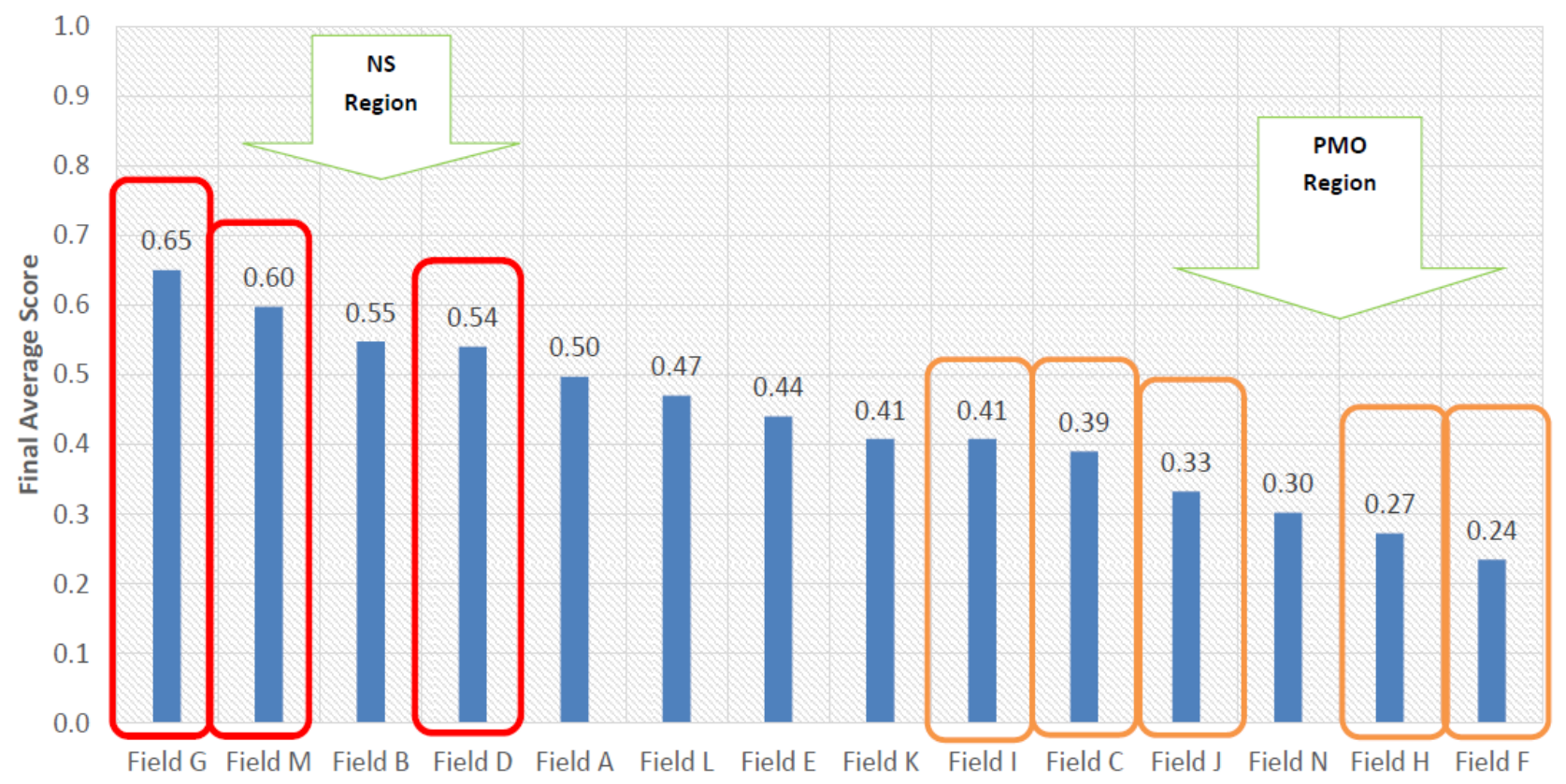

Figure 9: Overall risk ranking for all fields

Therefore, the recommended actions for this risk index is to perform comprehensive 3-D geomechanical modelling to evaluate top seal integrity and fault reactivation potential for various injection scenarios and stages. If the project team is planning to do injection under fracturing, it is highly recommended to perform fracture prediction (e.g., with REVEAL, PWRI-Frac or Frac-IT). In addition, the project team for Field $\mathrm{D}$ is advised to monitor for the critical locations based on the geomechanical model predictions.

Figure 8 shows the ranking for the sand problem issue for all fields. Only two threats that have been considered for this issue which are sand production during depletion (SPT-1) and sand production during injection (SPT-2). As a result, Field $\mathrm{G}$ has the highest final score which is ' 0.78 '. This is mainly due to the high effect sand production during depletion. The risk index for this field is ' 3 '. Therefore, the recommended actions for this risk index is to perform comprehensive sand production modelling, including formation characterization, rock mechanical characterization (UCS, TWC tests, etc.), and sanding estimation, e.g. with FIST.

Furthermore, Figure 9 summarizes the overall risk ranking for all field and thier regions. It is found that, North Sabah (NS) region i shaving higher geomechanical risk compared to Sarawak and Peninsular Malaysia (PMO). This is due to fact that majority of the oil and gas commercial accumulations were found in the Middle Miocene or younger clastic reservoirs in the Inboard Belt, Outboard Belt and East Baram Delta. The Inboard Belt is characterized by intense compressional features of the Sabah ridges separated by wide, deep synclines, particularly well-developed towards the western margin of the Belt. In the south, the main tectonic lineaments trend N-S and form a series of parallel, narrow wrenchrelated anticlines, with steep flanks and intensely faulted crest. The central part of the belt is tectonically more complex with both WNW-ESE and N-S trending tectonic features forming domal faulted fold interference patterns.

\section{Conclusion}

The questionnaires of screening criteria for geomechanical risk on development fields is successfully developed. This screening criteria can be used as a standard guideline for geomechanical study for all development fields. The result and discussion in the project is based on the geomechanical theory from the literature studied and the real assessment done towards relevant fields. Fourteen (14) identified development fields are selected for the assessment. These fields are from Baram Delta Operations (BDO) - 6 fields (Field E, A, L, K, B, N), North Sabah (NS) - 3 fields (Field G, D, $\mathrm{M})$ and Peninsular Malaysia Operations (PMO) -5 fields (Field J, I, F, H, C). Based on the assessment results, BDO and NS fields, comparing to PMO fields, have generally higher potential for geomechanics issues mainly due to the geological settings and formation characteristics.

Based on this study, the consequences towards people, asset, environment and reputation can be determined. This is very important due to the changes that occur to every field will affect all the 4 main aspects. Then, the level of effect is judged based on their severity. Moreover, there are also recommendation actions being suggested which was believed to help in reducing the risk of geomechanics. This mitigation are made differently for each threat which are drilling, depletion, injection \& storage and sand production. Also, the recommended actions are rank based on the level of impact towards each field. Final result indicate that fields in offshore Sabah is more critical or should be prioritize for geomechanics study compared to peninsular Malaysia 
and Sarawak regions because of the geological complexity in that area.

\section{References}

1. Sivakugan, N., S.K. Shukla, and B.M. Das, Rock Mechanics: an introduction. 2013: Crc Press.

2. Mody, F. and G. Wang. Application of geomechanics technology in borehole stability reduces well construction costs. in The 42nd US Rock Mechanics Symposium (USRMS). 2008. American Rock Mechanics Association.

3. Naterstad, T.L., Utilizing Managed Pressure Casing Drilling in Depleted Reservoir Zones. 2014.

4. Engle, C.J. and S.J. Marwil, Extracting and analyzing gas from well drilling mud. 1960, Google Patents.

5. Zoback, M.D., Reservoir geomechanics. 2010: Cambridge University Press.

6. Beck, E., et al., Concepts for Drilling and Excavating in and below the Ocean Bottom. 1971, DTIC Document.

7. Germanovich, L.N., et al. Poroelastic mechanism of fault reactivation as a result of reservoir depletion. in Pro\& ceedings of the Biot conference on poromechanics. 1998.

8. Nauroy, J.-F., Geomechanics applied to the petroleum industry. 2011: Editions Technip.

9. Collins, P.M. Geomechanical effects on the SAGD process. in SPE International Thermal Operations and Heavy Oil Symposium. 2005. Society of Petroleum Engineers.

10. Gor, G.Y., H.A. Stone, and J.H. Prévost, Fracture propagation driven by fluid outflow from a low-permeability aquifer. Transport in porous media, 2013. 100(1): p. 69-82.

11. Moeck, I., G. Kwiatek, and G. Zimmermann, Slip tendency analysis, fault reactivation potential and induced seismicity in a deep geothermal reservoir. Journal of Structural Geology, 2009. 31(10): p. 1174-1182.

12. Deichmann, N. and D. Giardini, Earthquakes induced by the stimulation of an enhanced geothermal system below Basel (Switzerland). Seismological Research Letters, 2009. 80(5): p. 784-798.

13. Muecke, T.W., Formation fines and factors controlling their movement in porous media. Journal of Petroleum Technology, 1979. 31(02): p. 144-150.

14. Bratli, R.K. and R. Risnes, Stability and failure of sand arches. Society of Petroleum Engineers Journal, 1981. 21(02): p. 236-248.

15. Nouri, A., et al., A comparison of two sanding criteria in physical and numerical modeling of sand production. Journal of petroleum science and engineering, 2006. 50(1): p. 55-70.

16. Alipour Tabrizy, V. and Y. Mirzaahmadian. Investigation of Sand Production Onset: A New Approach Based on Petrophysical Logs. in SPE
International Symposium and Exhibition on Formation Damage Control. 2012. Society of Petroleum Engineers.

17. Morita, N., et al., Realistic sand-production prediction: numerical approach. SPE Production Engineering, 1989. 4(01): p. 15-24. 